\title{
Penetrating Power of High-Density Tungsten Fiber/Zr-Based Metallic Glass Matrix Composite
}

\author{
Minming Zou $\mathbb{D}^{1},{ }^{1}$ Min Guo, ${ }^{2}$ and Xianghai $\mathrm{Ye}^{3}$ \\ ${ }^{1}$ College of Mechanical and Electrical Engineering, Zhejiang Business Technology Institute, Ningbo 315012, Zhejiang, China \\ ${ }^{2}$ Ningbo Branch of Chinese Academy of Ordnance Science, Ningbo 315103, Zhejiang, China \\ ${ }^{3}$ School of Mechanical Engineering and Mechanics, Ningbo University, Ningbo 315211, Zhejiang, China
}

Correspondence should be addressed to Minming Zou; zmmchp@126.com

Received 28 December 2021; Accepted 10 February 2022; Published 4 March 2022

Academic Editor: Dimitrios E. Manolakos

Copyright ( 12022 Minming Zou et al. This is an open access article distributed under the Creative Commons Attribution License, which permits unrestricted use, distribution, and reproduction in any medium, provided the original work is properly cited.

\begin{abstract}
Tungsten-fiber/Zr-based metallic glass $\left(\mathrm{Zr}_{41.25} \mathrm{Ti}_{13.75} \mathrm{Cu}_{12.5} \mathrm{Ni}_{10} \mathrm{Be}_{22.5}\right)$ matrix composite (hereinafter referred to as WF/Zr-MG composite) is considered a potential new generation of projectile material, while the density of WF/Zr-MG composite is usually around $16.5 \mathrm{~g} / \mathrm{cm}^{3}$ and it is difficult to exceed $17.0 \mathrm{~g} / \mathrm{cm}^{3}$. To understand the penetration performance of the composite material, a penetration test was performed on high-density WF/Zr-MG composite with a density of $17.1 \mathrm{~g} / \mathrm{cm}^{3}$. The penetration depth, the diameter of the crater, morphology, and microstructure have been studied in a residual high-density WF/Zr-MG composite penetrator. A total of 8 penetration tests were performed by firing the projectiles into 603 steel targets based on the $30 \mathrm{~mm}$ ballistic gun, which included five high-density WF/Zr-MG composite projectiles and three $93 \mathrm{~W}$ projectiles. Then, the target was cut through the crater using a wire cutting machine into a sample with $80 \mathrm{~mm} \times 40 \mathrm{~mm} \times 20 \mathrm{~mm}$, which was polished by different types of sandpaper. The microstructures were characterized and analyzed by SEM and TEM technology. According to this study, high-density WF/Zr-MG composite penetrators perforated the target with a thickness of $69.7 \mathrm{~mm}$ on average, which is about $19.8 \%$ better than $93 \mathrm{~W}$ alloy $(58.2 \mathrm{~mm})$ when the impact velocity is $1400 \pm 20 \mathrm{~m} / \mathrm{s}$. Meanwhile, the high-density WF/Zr-MG composites exhibited "self-sharpening" behavior in the penetration process. Moreover, the higher penetrating power of highdensity WF/Zr-MG composite is attributed to its higher dynamic compressive strength and "self-sharpening" behavior during penetration.
\end{abstract}

\section{Introduction}

Now, the two materials used for kinetic energy penetrators (KEP) are tungsten heavy alloy (WHA) and depleted uranium alloy (DUA). Unlike WHA, DUA fails by adiabatic shear when loaded in dynamic compression. As a result, when a DUA penetrator collides with the target plate at high speed, its nose remains sharp and about the same diameter as the rest of the penetrator and the sheared material is sloughed off. Thus, the kinetic energy is focused on a smaller area of the target, and the penetration depth is increased. This phenomenon is called "self-sharping". While, the nose of the WHA penetrator is like a "mushroom head" where the volume is bigger than that in the back, leaving a crater with a larger diameter. However, DUA is always not accepted because it emits low radiation to humans and the environment [1]. Consequently, a kind of better penetrator material is being searched for in the world [2-5].

Due to its excellent properties, including high-density and high-dynamic compressive strength, the tungsten fiber reinforced Zr-based metallic glass $\left(\mathrm{Zr}_{41.25} \mathrm{Ti}_{13.75} \mathrm{Cu}_{12.5} \mathrm{Ni}_{10} \mathrm{Be}_{22.5}\right)$ matrix (WF/Zr-MG) composite is considered as a potential new generation of projectile material to replace DUA and WHA $[6,7]$. Lots of research on WF/Zr-MG composite, which covers material design and preparation, fracture mode, and static and dynamic mechanical properties, have been reported in the past few years [8-11]. Conner et al. [6, 12], Du et al. [13], and Chen et al. $[7,14]$ conducted penetration tests to investigate the penetration power and failure of the WF/Zr-MG composite rods. The above investigations show that the 
composite rods failed by localized shear banding and displayed a "self-sharpening" behavior, and their armor-piercing power is about $10-20 \%$ better than that of WHA penetrators.

It is well known that the two desirable properties of KEP are "self-sharpening" behavior and high density, while the density of WF/Zr-MG composite is usually around $16.5 \mathrm{~g} /$ $\mathrm{cm}^{3}[6,13,14]$, difficult to exceed $17.0 \mathrm{~g} / \mathrm{cm}^{3}$ due to their inability to achieve close packing of tungsten wires.

In the present study, a penetration test was conducted on the WF/Zr-MG composite penetrator with a density of $17.1 \mathrm{~g} /$ $\mathrm{cm}^{3}$, which contains tungsten wire at $0.3 \mathrm{~mm}$ in diameter and $85 \%$ volume fraction, and $\mathrm{Zr}_{41.25} \mathrm{Ti}_{13.75} \mathrm{Cu}_{12.5} \mathrm{Ni}_{10} \mathrm{Be}_{22.5}$ bulk metallic glass at a $15 \%$ volume fraction. Meanwhile, the armor-piercing power, crater diameter in the stable penetration stage, and the morphology of the crater bottom of highdensity WF/Zr-MG composite projectiles were analyzed and compared with $93 \mathrm{~W}$ alloy projectiles.

\section{Materials and Methods}

The high-density WF/Zr-MG composite consists of Zrbased bulk metallic glass and tungsten fibers, and its density is $17.1 \mathrm{~g} / \mathrm{cm}^{3}$. The chemical composition of the bulk metallic glass is $\mathrm{Zr}_{41.25} \mathrm{Ti}_{13.75} \mathrm{Cu}_{12.5} \mathrm{Ni}_{10} \mathrm{Be}_{22.5}$, and tungsten fibers with $0.30 \mathrm{~mm}$ in diameter are homogeneously embedded in the matrix as the reinforced phase. The tungsten fibers occupy about $85 \%$ of the total volume. The picture of the high-density WF/Zr-MG composite is shown in Figure 1. The XRD pattern of this composite is shown in Figure 2(a), it can be seen that only the peaks of crystalline tungsten can be found, and no other crystalline phases are detected within the sensitivity limit of the XRD. Meanwhile, the TEM of the interface between the matrix and tungsten fiber is shown in Figure 2(b). As can be seen, no precipitated phase exists in this area, which is consistent with the XRD test results. The 93W alloy is made of $\mathrm{W}_{93} \mathrm{Ni}_{4} \mathrm{Fe}_{3}$, and its density is $17.3 \mathrm{~g} /$ $\mathrm{cm}^{3}$. The material density was measured by the MD-300S Archimedes density tester.

A total of 8 penetration tests were performed by firing the projectiles into 603 steel targets based on the $30 \mathrm{~mm}$ ballistic gun, in which five high-density WF/Zr-MG composite projectiles and three $93 \mathrm{~W}$ projectiles were included. The sizes of the projectile and target are $93 \mathrm{~mm}$ in height and $6 \mathrm{~mm}$ in diameter and $300 \mathrm{~mm} \times 200 \mathrm{~mm} \times 80 \mathrm{~mm}$ (length $\times$ width $\times$ thickness), respectively. The structure of the $105 \mathrm{~mm}$ simulated armor-piercing projectile as shown in Figure 3 has been used for more than 20 years in this paper, and its rationality has been fully verified. The material information of the projectile and target is given in Table 1, and the schematics of the experiment are schematically shown in Figure 4.

In this experiment, the speed of the projectile was measured by the high-speed camera and speed measurement system (XGK-2002, Xi'an Technological University, Xi'an, China). The speed of the projectile was adjusted to $1400 \pm 20 \mathrm{~m} / \mathrm{s}$ by the weight of the gunpowder. And the angle between the trajectory and target was $90^{\circ}$. After the penetration test, the target was cut through the crater using a wire cutting machine into a sample with $80 \mathrm{~mm} \times 40 \mathrm{~mm} \times 20 \mathrm{~mm}$

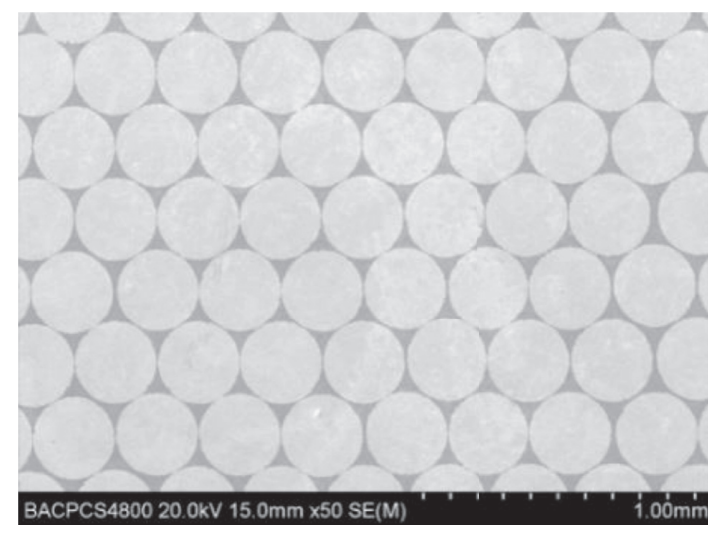

FIgURE 1: SEM morphology of high-density WF/Zr-MG composite.

(length $\times$ width $\times$ thickness), which was later polished by different types of sandpaper. Meanwhile, the penetration depth was measured. The crater diameter at the stable penetration stage, whose range is $24 \mathrm{~mm}-50 \mathrm{~mm}$ of penetration depth, and once per $2 \mathrm{~mm}$ is measured. The microstructure was observed by SEM (QUANTA FEG250, FEI Company, Hillsboro, OR, USA) and TEM (JEOL JEM-2800, JEOL, Tokyo, Japan). Meanwhile, the phase component of the composite is analyzed by XRD (Shimadzu XRD-6100, Shimadzu Corporation, Kyoto, Japan).

\section{Results}

3.1. Analysis of Penetrating Ability. In the case of $1400 \pm 20 \mathrm{~m} / \mathrm{s}$ impact, the front view of the target plate with eight craters is shown in Figure 5(a), and the back view of the target plate is shown in Figure 5(b), respectively. As shown in Figure 5, it can be seen that all projectiles are embedded in the target plate, not perforated through the target.

Furthermore, the impact velocity, mass, and depth of penetration of 8 projectiles are shown in Table 2, respectively. From Table 2, it can be seen that there is little difference in the mass of the two material projectiles, and the average thickness of the high-density WF/Zr-MG composite projectiles perforating the target is $69.7 \mathrm{~mm}, 19.8 \%$ higher than that of the $93 \mathrm{~W}$ alloy $(58.2 \mathrm{~mm})$. In other words, the penetrator power of the high-density WF/Zr-MG composite is significantly higher than that of the $93 \mathrm{~W}$ alloy.

Meanwhile, the kinetic energy of the projectile can be calculated by as follows:

$$
E=\frac{1}{2} m v^{2}
$$

where $E, m$, and $v$ are the kinetic energy, the mass, and the impact velocity of the projectile, respectively. And then $E^{\prime}$ is defined as the ratio of $E$ to $p$, which is expressed as

$$
E^{\prime}=\frac{E}{p}
$$

where $p$ is the penetrating depth of the projectile. The $E^{\prime}$ of two different material projectiles is shown in Figure 6, it can be seen that the $E^{\prime}$ of five high-density WF/Zr-MG 


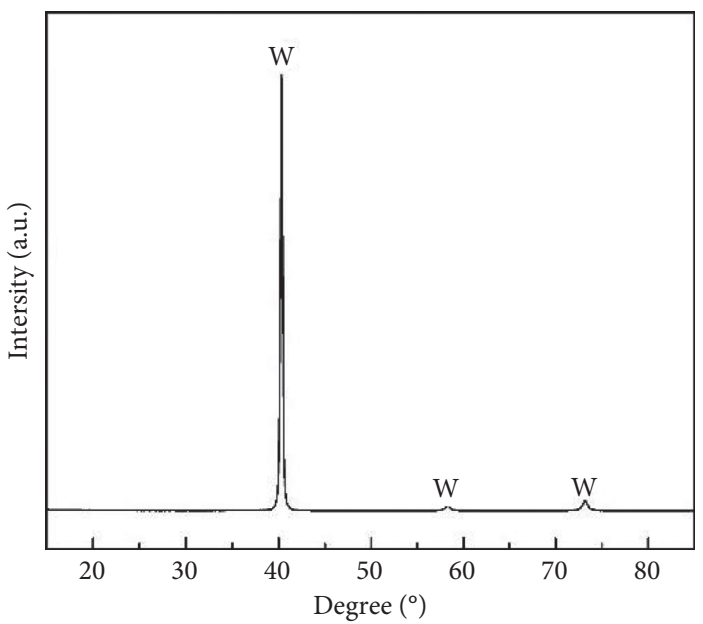

(a)

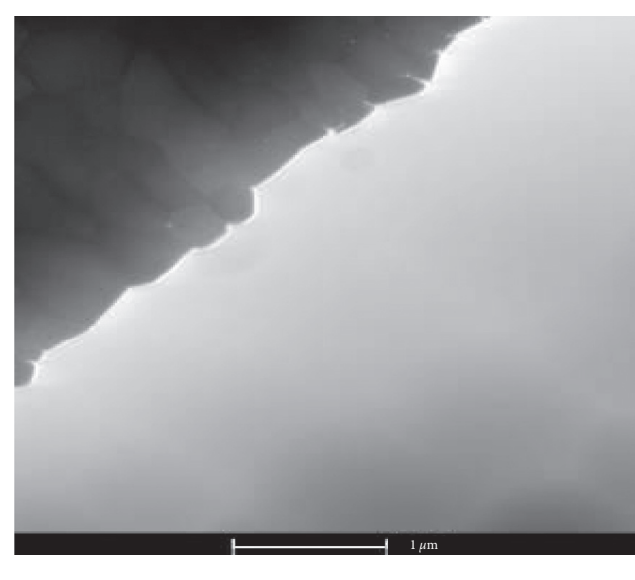

(b)

Figure 2: XRD (a) and TEM images (b) of high-density WF/Zr-MG composite.

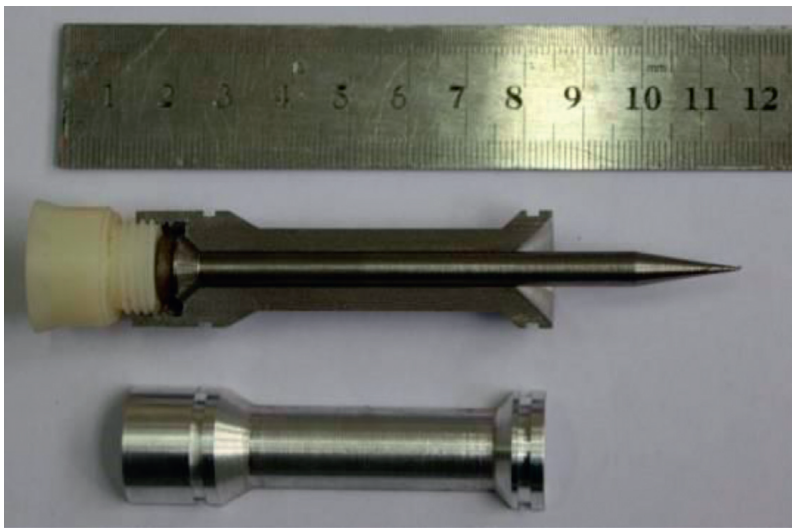

FIGURE 3: $105 \mathrm{~mm}$ simulated armor-piercing projectile.

TABLE 1: Materialinformation of projectile and target.

\begin{tabular}{|c|c|c|c|}
\hline \multicolumn{2}{|c|}{ Condition } & Chemical composition & Original structure of material \\
\hline Projectile & $\begin{array}{l}\text { High-density } \\
\text { WF/Zr-MG } \\
\text { 93W }\end{array}$ & $\begin{array}{c}85 \% \mathrm{~W} 15 \% \mathrm{Zr}_{41.25} \mathrm{Ti}_{13.75} \mathrm{Cu}_{12.5} \mathrm{Ni}_{10} \mathrm{Be}_{22.5} \text { (volume fraction) } \\
\qquad \mathrm{W}_{93} \mathrm{Ni}_{4} \mathrm{Fe}_{3}\end{array}$ & $\begin{array}{l}\text { Crystal structure of tungsten } \\
\text { fiber + amorphous matrix } \\
\text { Liquid-phase sintering }\end{array}$ \\
\hline Target & & $\begin{array}{c}0.37-0.44 \% \mathrm{C}, 0.17-0.37 \% \mathrm{Si}, 0.5-0.8 \% \mathrm{Mn}, 0.6-0.9 \% \mathrm{Cr}, 0.15-0.25 \% \mathrm{Mo} \\
0.5-0.8 \% \mathrm{~W}, \leq 0.3 \% \mathrm{~S}, 0.25-1.65 \% \mathrm{Ni} \text { (weight fraction) }\end{array}$ & Sorbite \\
\hline
\end{tabular}

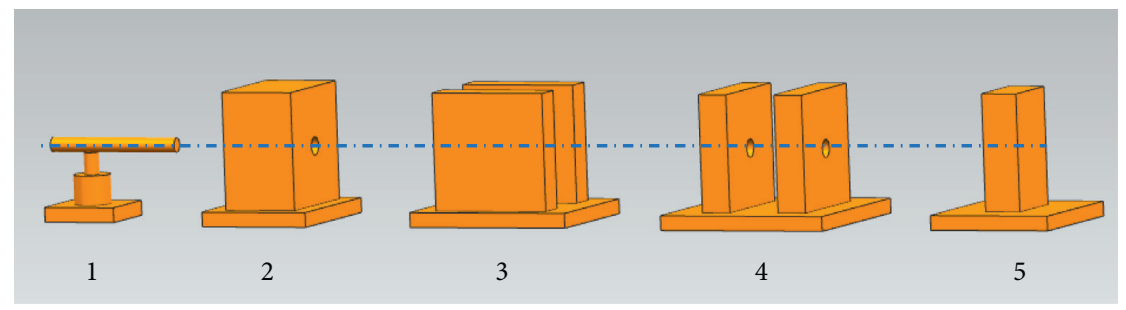

Figure 4: Schematics of the ballistic experiment: 1 is a $30 \mathrm{~mm}$ ballistic gun, 2 is the sabot collector, 3 is a high-speed camera, 4 is a speed measurement system, and 5 is the target.

composite projectiles is $669.5 \mathrm{~J} / \mathrm{mm}, 615.9 \mathrm{~J} / \mathrm{mm}, 619.3 \mathrm{~J} /$ $\mathrm{mm}, 628.9 \mathrm{~J} / \mathrm{mm}$, and $605.8 \mathrm{~J} / \mathrm{mm}$, respectively. However, the $E^{\prime}$ of the three $93 \mathrm{~W}$ alloy projectiles is $756.4 \mathrm{~J} / \mathrm{mm}$,
$746.5 \mathrm{~J} / \mathrm{mm}$, and $748.7 \mathrm{~J} / \mathrm{mm}$, respectively, which is significantly higher than that of the high-density WF/Zr-MG composite projectiles. The figures above state that the 


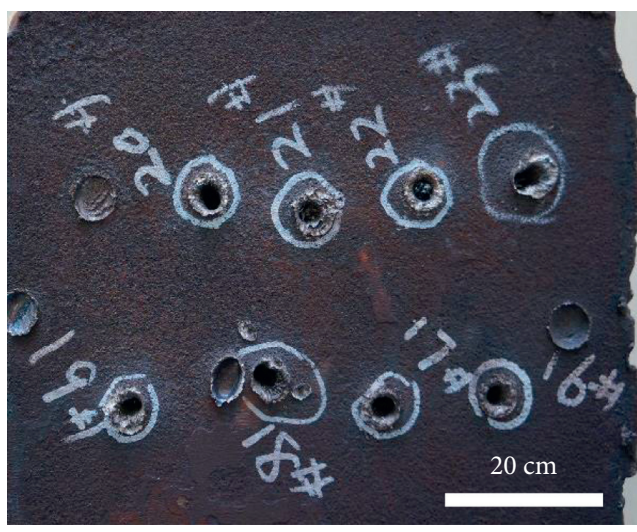

(a)

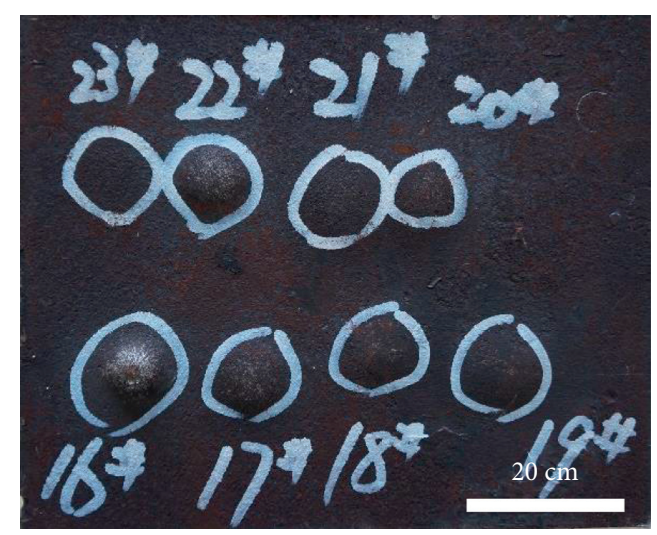

(b)

FIGURE 5: View of the target plate after penetration of the front (a) and back (b).

TABLe 2: Impact velocity, mass, and penetration depth of projectiles.

\begin{tabular}{|c|c|c|c|c|}
\hline Projectile materials & Mass (g) & Impact velocity $(\mathrm{m} / \mathrm{s})$ & Depth of penetration $(\mathrm{mm})$ & Average depth of penetration $(\mathrm{mm})$ \\
\hline \multirow{5}{*}{ High-density WF/Zr-MG composite } & 44.1 & 1407 & 65.2 & \multirow{5}{*}{69.7} \\
\hline & 44.3 & 1409 & 71.4 & \\
\hline & 44.3 & 1402 & 70.3 & \\
\hline & 44.1 & 1416 & 70.3 & \\
\hline & 44.2 & 1398 & 71.3 & \\
\hline \multirow{3}{*}{ 93W alloy } & 44.5 & 1392 & 57.0 & \multirow{3}{*}{58.2} \\
\hline & 44.6 & 1403 & 58.8 & \\
\hline & 44.3 & 1411 & 58.9 & \\
\hline
\end{tabular}

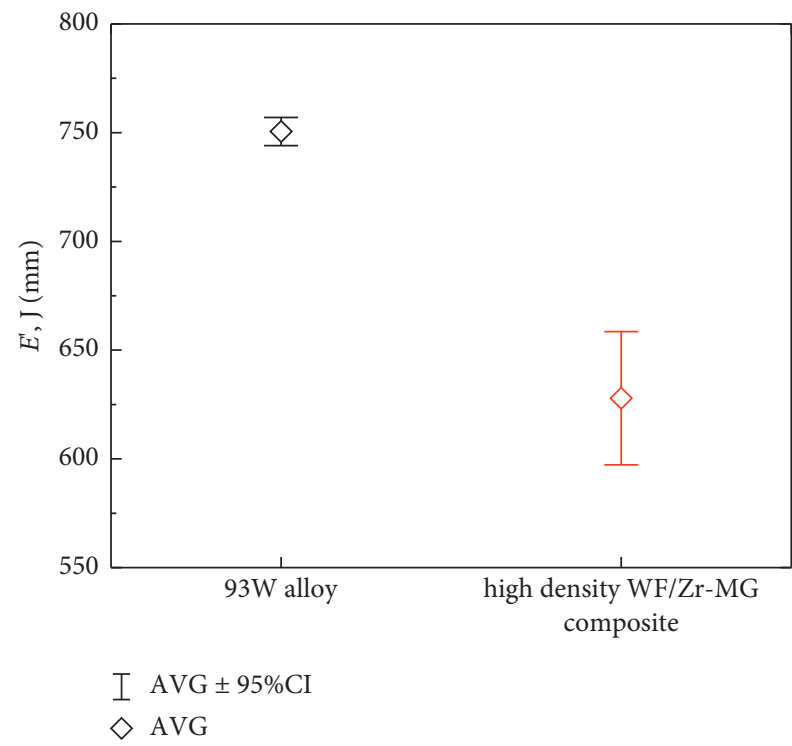

Figure 6: The $E^{\prime}$ of two different material projectiles.

projectiles of the high-density WF/Zr-MG composite have higher penetrator efficiency than those of the $93 \mathrm{~W}$ alloy when they have the same kinetic energy at $43 \mathrm{~kJ}$.

3.2. Characteristics of Penetration Crater. The post-test longitudinal sections of 603 steel targets fired by highdensity WF/Zr-MG composite and $93 \mathrm{~W}$ alloy projectiles are displayed in Figures 7(a) and 7(b), respectively. It can be seen that the residual high-density WF/Zr-MG composite and $93 \mathrm{~W}$ alloy projectiles filled the craters. Besides, the bottom of the crater penetrated by $93 \mathrm{~W}$ alloy projectiles is rough and clearly blunt, mainly resulting from the material plastic flowing and little erosion. Besides, further analysis shows that the average diameter of the $93 \mathrm{~W}$ alloy projectile penetrating a crater is $11.0 \mathrm{~mm}$, which is about 1.8 times its initial diameter.

By comparison, when the projectile material is a high-density WF/Zr-MG composite, the trajectory is straight and smooth, and a narrow tunnel through the target is created. Results show that the average diameter of the high-density WF/Zr-MG composite projectiles penetrating a crater is $8.2 \%$ smaller than the former, which is $10.1 \mathrm{~mm}$, approximately 1.6 times the penetrator diameter.

Overall, the diameter of the ballistic hole bored by the 93W alloy projectile is larger than that of the high-density $\mathrm{WF} / \mathrm{Zr}-\mathrm{MG}$ composite projectile, which indicates that the more kinetic energy of the $93 \mathrm{~W}$ alloy projectile is used for expanding the diameter of the penetrating crater, resulting in a decrease in the depth of penetration.

3.3. Microstructure Analyses on the Residual Penetrators. The head of the $93 \mathrm{~W}$ alloy residual projectile, as shown in Figure 8, experienced a series of deformations under the condition of high-speed impact, as shown in Figure 9, and the locations are marked as seen in Figure 8. Clearly, 


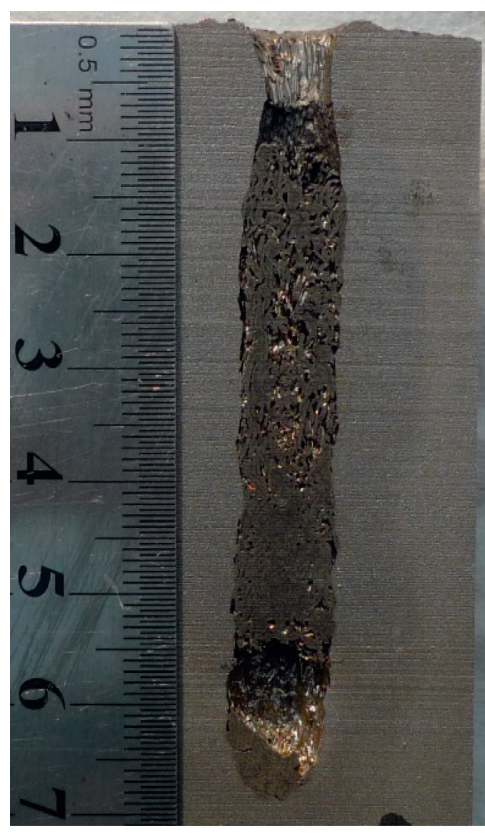

(a)

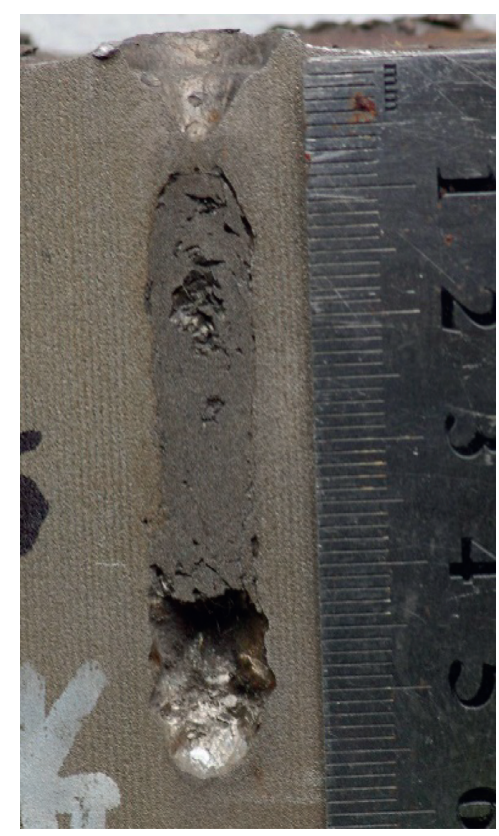

(b)

Figure 7: Craters of high-density WF/Zr-MG composite (a) and 93W alloy penetrators (b).

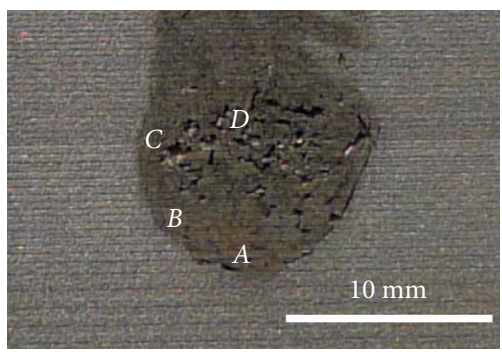

FIGURE 8: OM image of the head of $93 \mathrm{~W}$ alloy residual projectile.

the strong impact changed the $93 \mathrm{~W}$ alloy grains on the top of the head of the residual projectile (marked as position $A$ ) changed into flat particles, and the long-axis direction of the elongated grain substantially is perpendicular to the direction of penetration, as displayed in Figure $9(\mathrm{a})$. In positions $B, C$, and $D$, the tensile and compressive deformation of $93 \mathrm{~W}$ alloy grains occurred on the lateral side of the residual projectile head. In the positions closer to the top edge of the head of the residual projectile, e.g., positions $B$ and $C$, a remarkable deformation of $93 \mathrm{~W}$ alloy grains is observed. Those elongated grains are displayed as the fibrous shape, and its long-axis direction is the same as the streamlined direction of the head of the residual projectile. Then, the 93W alloy grains did not break at the contact location between the head of the residual projectile and the target. It is because of the dislocation movement along the direction of the maximum shear stress that results in the plastic deformation of $93 \mathrm{~W}$ alloy grains. It indicates that the $93 \mathrm{~W}$ alloy has good plasticity under high-speed penetration, resulting in the formation of "mushroom head".
By comparison, the head of the residual high-density $\mathrm{WF} / \mathrm{Zr}-\mathrm{MG}$ composite projectile is studied when the impact speed is $1400 \pm 20 \mathrm{~m} / \mathrm{s}$. The result can be seen in Figure 10. It can be seen that the residual high-density WF/Zr-MG composite projectile head is sharper than that of the $93 \mathrm{~W}$ alloy. Meanwhile, the microstructure of the positions of the $E-F$ and G-F lines that are drawn in Figure 10 is further studied, which is shown in Figure 11. On the bottom left and right bottom, one can see that the tungsten fiber initially aligned with the projectile longitudinal axis, bends and shears along a line oriented about $45^{\circ}$ angle to the longitudinal axis. And these wires are then sloughed off, at $90^{\circ}$ including an angle between the two sheared faces is created, and then the tip is sharpened effectively, which is called the "self-sharpening" phenomenon. The "self-sharpening" leads to a sharper nose for high-density WF/Zr-MG composite projectiles, and it effectively improves the penetration capability.

\section{Discussion}

In terminal ballistics, relatively simple engineering models are irreplaceable. No matter how great the achievements of numerical simulation technology could be, an engineering model that is based on the most important and characteristic physical processes of projectile-target interaction could give the main trends and principal results of the projectile-target interaction.

The Alekseevskii-Tate model [15] is the most successful semihydrodynamic model applied to long-rod penetration into semiinfinite targets. This is a one-dimensional model of long-rod penetration derived from hydrodynamic theory $[16,17]$. Rod and target strength are included in the modified Bernoulli equations. This 


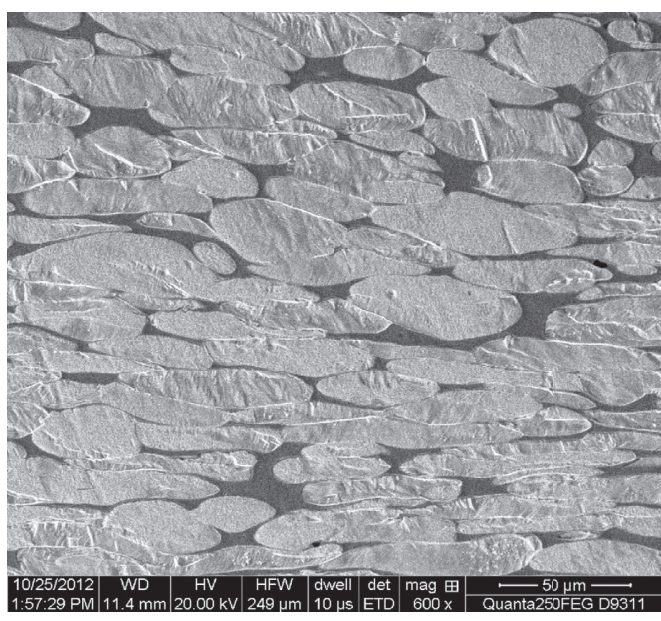

(a)

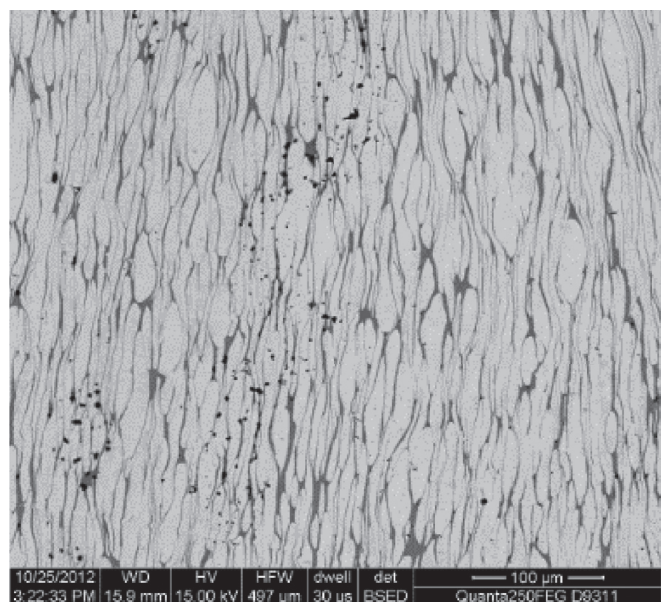

(c)

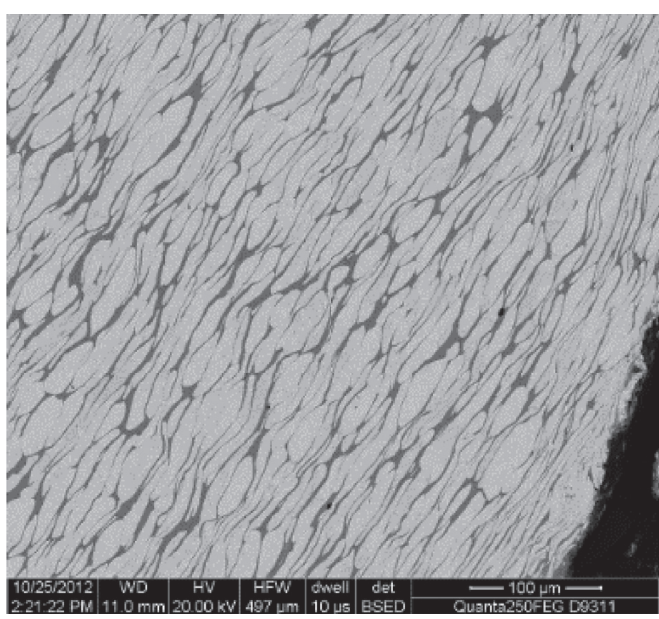

(b)

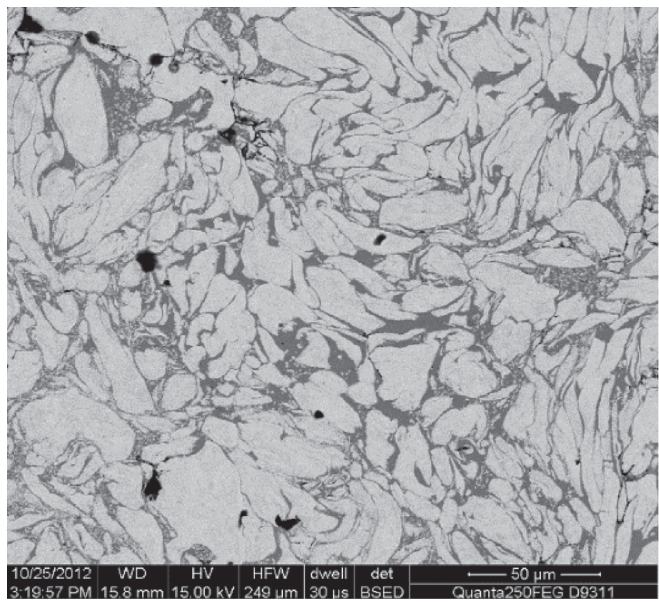

(d)

FIGURE 9: SEM photographs of the head of the residual projectile of 93W alloy in different positions of Figure 8: (a) in position $A$, (b) in position $B$, (c) in position $C$, and (d) in position $D$.

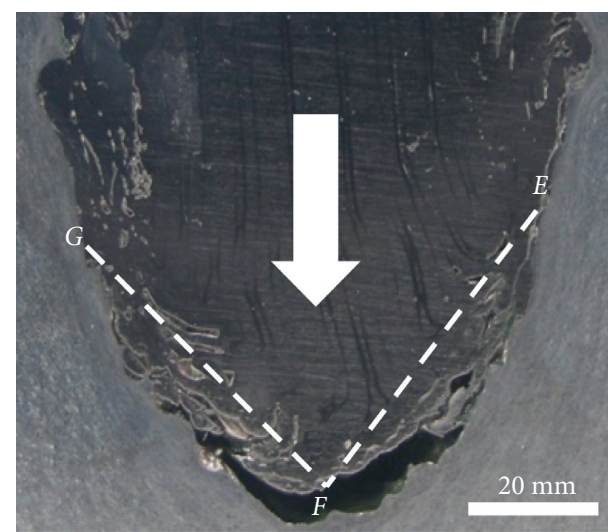

FIGURe 10: Photo of the residual high-density WF/Zr-MG composite penetrator nose.

semifluid model assumes that the projectile is rigid, except for an infinitesimally thin region near the target-projectile interface where erosion is occurring in a fluid manner. The model also assumes balanced stress and a consecutive velocity at the interface, which means the penetration

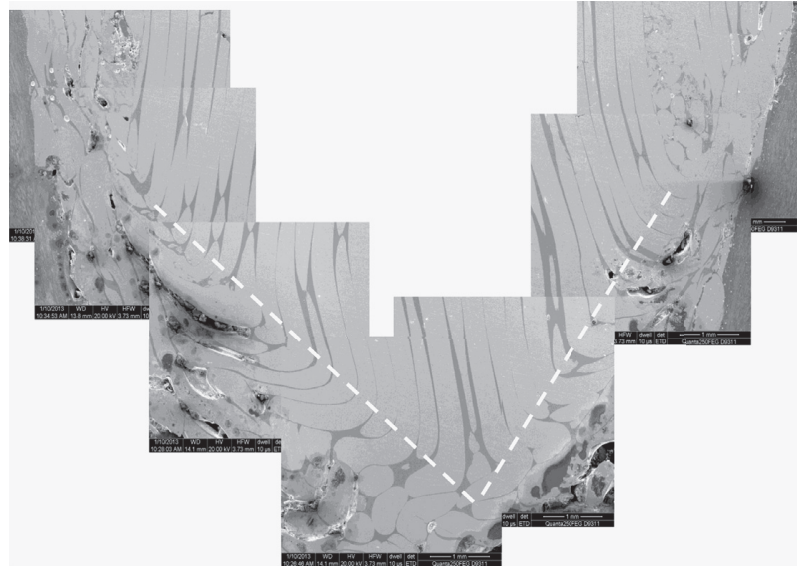

FIgUre 11: Zooming photos of the positions of E-F and G-F lines.

velocity is equal to the nose velocity of the projectile, and the deceleration of the rear of the projectile is governed by the flow stress of the projectile. The governing equations are given as follows: 


$$
\frac{1}{2} \rho_{p}(v-u)^{2}+Y_{p}=\frac{1}{2} \rho_{t} u^{2}+R_{t}
$$

where $Y_{p}$ is the dynamic yield strength of the rod material, and $R_{t}$ is the target resistance to penetration. $R_{t}$ is related to material strength and can be calculated approximately with cavity expansion theory. $v$ is the rod velocity. $u$ is the penetration velocity, and $u<v$. Equation (1), together with the following equations, provides a complete solution of the long-rod penetration problem:

$$
\begin{aligned}
\rho_{p} l^{\prime} \frac{d v}{d t} & =-Y_{p} \\
\frac{d l^{\prime}}{d t} & =-(v-u) \\
p & =\int_{v_{0}}^{v_{c}} u d t
\end{aligned}
$$

Here, equation (4) is the rod deceleration equation, equation (5) is the length of the penetrator consumption equation, and equation (6) is the penetration depth equation. $p$ is the penetration depth, $l^{\prime}$ is the residual rod length, $v_{c}$ stands for the critical tail velocity, and the long-rod semihydrodynamic penetration initiates only if $v>v_{c}$.

From equation (3), the penetration velocity $u$ can be written as follows:

$$
u=\frac{\rho_{p} v}{\rho_{p}-\rho_{t}}-\sqrt{\frac{2\left(R_{t}-Y_{p}\right)+\rho_{p} \rho_{t} / \rho_{p}-\rho_{t} v^{2}}{\rho_{p}-\rho_{t}}}
$$

The above equation is the expression that correlates the penetration velocity $u$ and these parameters such as the rod velocity $v$, the densities of projectile and target material $\left(\rho_{p}, \rho_{t}\right)$, the penetration resistance of target $R_{t}$, and the dynamic flow stress of projectile material $Y_{p}$, which are listed in Table 2, respectively.

Penetration velocity $u$ is an important parameter in longrod penetration. If the value of $u$ is greater than the condition of the rod velocity, $v$ is known from equation (5), the rod length is eroded more slowly, and the residual rod length $l^{\prime}$ (mass) is larger, which indicates that the penetration ability of the rod will be better.

As can be seen in Table 3, the densities of high-density $\mathrm{WF} / \mathrm{Zr}-\mathrm{MG}$ composite and $93 \mathrm{~W}$ alloy are almost at the same value, and 603 steel target density $\rho_{t}$ and resistance $R_{t}$ are $7.85 \mathrm{~g} / \mathrm{cm}^{3}$ and $6000 \mathrm{MPa}$, respectively. However, the dynamic yield strength $Y_{p}$ of the high-density WF/Zr$\mathrm{MG}$ is $3000 \mathrm{MPa}$, which is higher than that of $93 \mathrm{~W}$ alloy with a strain rate of $3000 \mathrm{~s}^{-1}$. According to equation (7), it can be found that the penetration velocity $u$ of the highdensity WF/Zr-MG composite penetrator is larger than that of the $93 \mathrm{~W}$ alloy penetrator when these penetrators have the same velocity $v$. In other words, the penetration ability of the high-density WF/Zr-MG composite penetrator is better than that of the $93 \mathrm{~W}$ alloy penetrator with the same penetration conditions, such as mass and impact velocity.
TABLE 3: Material information of projectile and target.

\begin{tabular}{lcccc}
\hline Material & $\begin{array}{c}Y_{p} \\
(\mathrm{MPa})\end{array}$ & $\begin{array}{c}R_{t} \\
(\mathrm{MPa})\end{array}$ & $\begin{array}{c}\rho_{t}(\mathrm{~g} / \\
\left.\mathrm{cm}^{3}\right)\end{array}$ & $\begin{array}{c}\rho_{p}(\mathrm{~g} / \\
\left.\mathrm{cm}^{3}\right)\end{array}$ \\
\hline $\begin{array}{l}\text { High-density WF/Zr- } \\
\text { BG }\end{array}$ & $3000[18]$ & - & - & 17.1 \\
93W alloy & $2000[19]$ & - & - & 17.3 \\
603 steel & - & $\begin{array}{c}6000 \\
{[19]}\end{array}$ & 7.85 & - \\
\hline
\end{tabular}

Besides, an obvious "self-sharpening" phenomenon occurs in the head of the high-density WF/Zr-MG composite penetrator, as shown in Figures 10 and 11. It decreases the penetration resistance and increases the penetration ability, and thereby it decreases the diameter of the bullet hole and increases the depth of penetration, as shown in Table 2 and Figure 7, respectively. While, the material continuity exactly exists between the mushroom head and the $93 \mathrm{~W}$ alloy penetrator body, which increases the diameter of the $93 \mathrm{~W}$ alloy penetrator head and bullet hole.

\section{Conclusions}

(1) High-density WF/Zr-MG composite penetrators perforated the target with a thickness of $69.7 \mathrm{~mm}$ averagely, which is significantly higher than $19.8 \%$ better than that of $93 \mathrm{~W}$ alloy $(58.2 \mathrm{~mm})$, when the impact velocity is $1400 \pm 20 \mathrm{~m} / \mathrm{s}$. Meanwhile, the penetration efficiency of the high-density WF/ZrMG composite is higher than that of the $93 \mathrm{~W}$ alloy.

(2) The average diameter of the high-density WF/ZrMG composite projectiles penetrating the crater is $10.1 \mathrm{~mm}$, approximately 1.6 times the penetrator diameter, which is $8.2 \%$ smaller than that of $93 \mathrm{~W}$ alloy projectiles. Meanwhile, the high-density WF/ Zr-MG composite exhibited "self-sharpening" behavior in the process of penetration, which led to a sharper nose for high-density WF/Zr-MG composite projectiles.

(3) The higher penetrating power of high-density WF/ $\mathrm{Zr}-\mathrm{MG}$ composite projectiles is attributed to its higher dynamic compressive strength and "self-sharpening" behavior during penetration.

\section{Data Availability}

The data used to support the findings of this study are plotted within the article, and the raw data files are available by contacting the corresponding author.

\section{Conflicts of Interest}

The authors declare that there are no conflicts of interest.

\section{Authors' Contributions}

Conceptualization: Minming Zou and Xianghai Ye; formal analysis: Minming Zou and Min Guo; investigation: Minming Zou and Min Guo.; data curation: Min Guo and 
Minming Zou; writing-original draft preparation: Minming Zou and Xianghai Ye; and writing-review and editing: Min Guo and Xianghai Ye. All authors have read and agreed to the published version of the manuscript.

\section{Acknowledgments}

This study was supported by the General Scientific Research Project of Education Department of Zhejiang Province (Y202147924), the Natural Science Foundation of Zhejiang Province (LQ14F040004), the Ningbo Public Welfare Science and Technology Project (20211JCGY020484), and the Scientific research and innovation team project of Zhejiang Business Technology Institute (KYTD202105).

\section{References}

[1] A. Bleise, P. R. Danesi, and W. Burkart, "Properties, use and health effects of depleted uranium (DU): a general overview," Journal of Environmental Radioactivity, vol. 64, no. 2-3, pp. 93-112, 2003.

[2] L. S. Magness, D. Kapoor, and R. Dowding, "Novel flowsoftening and flow-anisotropy approaches to developing improved tungsten kinetic energy penetrator materials," Materials and Manufacturing Processes, vol. 10, no. 3, pp. 531-540, 1995.

[3] S. Pappu, C. Kennedy, E. L. Murr, L. S. Magness, and D. Kapoor, "Microstructure analysis and comparison of tungsten alloy rod and [001] oriented columnar-grained tungsten rod ballistic penetrators," Materials Science and Engineering: A, vol. 262, no. 1-2, pp. 115-128, 1999.

[4] S. Pappu, S. Sen, L. E. Murr, D. Kapoor, and L. S. Magness, "Deformation twins in oriented, columnar-grained tungsten rod ballistic penetrators," Materials Science and Engineering: A, vol. 298, no. 1-2, pp. 144-157, 2001.

[5] E. A. Trillo, E. V. Esquivel, L. E. Murr, and L. S. Magness, "Dynamic recrystallization induced flow phenomenon in tungsten-tantalum (4\%) [001] single-crystal rod ballistic penetrators," Materials Characterization, vol. 48, pp. 407-421, 2002.

[6] R. D. Conner, R. B. Dandliker, V. Scruggs, and W. L. Johnson, "Dynamic deformation behavior of tungsten-fiber/metallicglass matrix composites," International Journal of Impact Engineering, vol. 24, no. 5, pp. 435-444, 2000.

[7] J. H. Chen, Y. Chen, M. Q. Jiang et al., "Direct observation on the evolution of shear banding and buckling in tungsten fiber reinforced Zr-based bulk metallic glass composite," Metallurgical and Materials Transactions A, vol. 45, no. 12, pp. 5397-5408, 2014.

[8] S.-B. Lee, S.-K. Lee, S. Lee, and N. J. Kim, "Microstructure and mechanical properties of two continuous-fiber-reinforced $\mathrm{Zr}$ based amorphous alloy composites fabricated by liquid pressing process," Metallurgical and Materials Transactions A, vol. 39, no. 4, pp. 763-771, 2008.

[9] C.-Y. Son, G. S. Kim, S.-B. Lee, S.-K. Lee, H. S. Kim, and S. Lee, "Dynamic compressive properties of $\mathrm{Zr}$-based amorphous matrix composites reinforced with tungsten continuous fibers or porous foams," Metallurgical and Materials Transactions A, vol. 43, no. 6, pp. 1911-1920, 2012.

[10] G. Wang, D. M. Chen, J. Shen et al., "Deformation behaviors of a tungsten-wire/bulk metallic glass matrix composite in a wide strain rate range," Journal of Non-crystalline Solids, vol. 352, no. 36-37, pp. 3872-3878, 2006.
[11] H. Wang, H. F. Zhang, and Z. Q. Hu, "Tungsten fibre reinforced Zr-based bulk metallic glass composites," Materials and Manufacturing Processes, vol. 22, no. 6, pp. 687-691, 2007.

[12] R. D. Conner, R. B. Dandliker, and W. L. Johnson, "Mechanical properties of tungsten and steel fiber reinforced Zr41.25Ti13.75Cu12.5Ni10Be22.5 metallic glass matrix composites," Acta Materialia, vol. 46, no. 17, pp. 6089-6102, 1998.

[13] C. X. Du, D. W. Shu, Z. H. Du et al., "Effect of L/D on penetration performance of tungsten fibre/Zr-based bulk metallic glass matrix composite rod," Int. J. Refract. Hard. Met, vol. 85, pp. 1-9, 2019.

[14] X. W. Chen, L. M. Wei, and J. C. Li, "Experimental research on the long rod penetration of tungsten-fiber/Zr-based metallic glass matrix composite into Q235 steel target," International Journal of Impact Engineering, vol. 79, pp. 102-116, 2015.

[15] V. P. Alekseevskii, "Penetration of a rod into a target at high velocity," Combustion, Explosion and Shock Waves, vol. 2, pp. 63-66, 1966.

[16] A. Tate, "A theory for the deceleration of long rods after impact," Journal of the Mechanics and Physics of Solids, vol. 15, no. 6, pp. 387-399, 1967.

[17] A. Tate, "Further results in the theory of long rod penetration*," Journal of the Mechanics and Physics of Solids, vol. 17, no. 3, pp. 141-150, 1969.

[18] M. M. Zou, M. Guo, D. S. Cai, G. Xu, K. W. Tian, and L. J. Zhu, "Morphological characteristics of penetration crater of tungsten wire reinforced zirconium based amorphous matrix composite," Ordnance Material Science and Engineering, vol. 44, no. 4, pp. 56-60, 2021.

[19] L. S. Zhang and F. L. Huang, "Model for long-rod penetration into semi-infinite targets," Journal of Beijing Institute of Technology (Social Sciences Edition), vol. 13, no. 5, pp. 285-289, 2004. 